\title{
LATE PROGNOSIS OF SEVERE HEAD INJURIES IN CHILDHOOD*
}

\author{
BY
}

BO HJERN and INGVAR NYLANDER

From the Department of Paediatric Surgery, and the Child Psychiatric Department, Kronprinsessan Lovisas Barnsjukhus, Stockholm, Sweden

Slight head injuries resulting in a short period of unconsciousness have been the object of intensive research. Early as well as late prognosis has accounted for a series of investigations both in adults and children. Contributory reasons for this great interest have been, on the one hand, that head injuries of this type are very common and, on the other hand, that knowledge of their character and long-term significance is still incomplete. The comparatively rare serious head injuries resulting in a long period of unconsciousness manifest themselves in a different manner. There have only been a few separate investigations of their late prognosis, and no accounts have been found in the literature, which deal thoroughly with the late prognosis for children with serious head injuries.

With the increasing mechanization of modern society and above all the increasing traffic the frequency of serious head injuries has risen. At the same time the likelihood of surviving acute, serious head injuries has increased due to advances in modern emergency surgery. Problems involving the care of the patient with serious head injury have, therefore, become more extensive. The emergency care as well as the following rehabilitation are burdensome and costly and require considerable contributions from the nursing staff and the community as well as from the patient and his family. Therefore, it would be of interest to

* A paper read at a meeting of the British Association of Paediatric Surgeons in Stockholm, September 1961. have reliable information not only on the nature and extent of these injuries, but most of all on their prognoses. The surgeons who see their patients unconscious for long periods of time, often ask themselves if the victims will ever again be completely normal persons, or if they will remain charges for the remainder of their lives.

The present investigation is a contribution to the discussion of the prognosis of the serious head injury. Åkerlund (1959) reported encouraging results in an investigation of 26 patients, each of whom had been unconscious for more than a week. Eight of these patients who were completely without symptoms and fit enough to work were under 24 years of age. Other investigations of head injuries, for example, Cedermark's (1942) thesis, comprising about 2,000 cases of head injuries of different types and severity, indicate a more favourable prognosis in the lower age groups than in the higher.

\section{Material and Methods}

The department of Paediatric Surgery of the Kronprinsessan Lovisas Barnsjukhus (KLB) annually cares for between 300 and 600 children with acute head injuries. The case material of the department for the past 10 years is shown in Table 1. Those with head injuries constitute between 9 and $17 \%$ of the total number of children cared for. About two-thirds of these are boys. In only two cases has death followed the head injury. This

TABLE 1

ADMISSIONS OF CHILDREN WITH HEAD INJURIES TO THE SURGICAL CLINIC AT KRONPRINSESSAN LOVISAS BARNSJUKHUS, 1951-1960

\begin{tabular}{|c|c|c|c|c|c|c|c|c|c|c|c|c|c|c|c|}
\hline Year .. & . & .. & . & . & .. & 1951 & 1952 & 1953 & 1954 & 1955 & 1956 & 1957 & 1958 & 1959 & 1960 \\
\hline $\begin{array}{l}\text { Boys } \ldots \\
\text { Girls } \quad . \\
\text { Boys (\%) } \\
\text { Dead } . .\end{array}$ & $\begin{array}{l}\cdots \\
\cdots \\
\cdots\end{array}$ & $\begin{array}{l}\cdots \\
\cdots \\
\cdots \\
\cdots\end{array}$ & $\begin{array}{l}\cdots \\
\cdots \\
\cdots \\
\cdots\end{array}$ & $\begin{array}{l}\cdots \\
\cdots \\
\cdots \\
\cdots\end{array}$ & $\begin{array}{l}\ldots \\
\ldots \\
. \\
. \\
.\end{array}$ & $\begin{array}{r}223 \\
91 \\
314 \\
71\end{array}$ & $\begin{array}{r}302 \\
127 \\
429 \\
70\end{array}$ & $\begin{array}{r}405 \\
195 \\
600 \\
68 \\
1\end{array}$ & $\begin{array}{r}377 \\
211 \\
588 \\
64\end{array}$ & $\begin{array}{r}314 \\
159 \\
473 \\
66\end{array}$ & $\begin{array}{r}273 \\
150 \\
423 \\
65 \\
1\end{array}$ & $\begin{array}{r}241 \\
109 \\
350 \\
69\end{array}$ & $\begin{array}{r}228 \\
110 \\
338 \\
67\end{array}$ & $\begin{array}{r}395 \\
136 \\
531 \\
74\end{array}$ & $\begin{array}{r}297 \\
145 \\
442 \\
67\end{array}$ \\
\hline$\%$ head in & 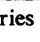 & at & 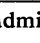 & & $\cdots$ & $9 \cdot 8$ & $11 \cdot 9$ & $17 \cdot 1$ & $15 \cdot 3$ & $12 \cdot 6$ & $12 \cdot 2$ & $9 \cdot 3$ & $9 \cdot 8$ & $12 \cdot 4$ & $11 \cdot 8$ \\
\hline
\end{tabular}


TABLE 2

DURATION OF UNCONSCIOUSNESS

\begin{tabular}{|c|c|}
\hline $\begin{array}{l}\text { No. of Days } \\
\text { Unconscious }\end{array}$ & $\begin{array}{l}\text { No. of } \\
\text { Cases }\end{array}$ \\
\hline $\begin{array}{c}1 \\
2 \\
3 \\
4 \\
5 \\
6 \\
7 \\
8 \\
9 \\
10 \\
11 \\
12 \\
13 \\
14 \\
15-21 \\
22-28 \\
>28\end{array}$ & $\begin{array}{l}2 \\
3 \\
3 \\
3 \\
- \\
1 \\
- \\
- \\
3 \\
1 \\
1 \\
3 \\
1 \\
2\end{array}$ \\
\hline
\end{tabular}

TABLE 3

AGE AT TIME OF TRAUMA

\begin{tabular}{c|c|c}
\hline $\begin{array}{c}\text { Age } \\
\text { (years) }\end{array}$ & $\begin{array}{c}\text { No. of } \\
\text { Boys }\end{array}$ & $\begin{array}{c}\text { No. of } \\
\text { Girls }\end{array}$ \\
\hline 1 & 1 & - \\
2 & $\frac{1}{3}$ & 1 \\
4 & 4 & 1 \\
5 & 1 & $=$ \\
6 & 3 & - \\
7 & 2 & - \\
8 & 1 & $=$ \\
9 & - & $=$ \\
11 & 1 & 1 \\
12 & 2 & $=$ \\
13 & 1 & $=$ \\
\hline
\end{tabular}

low mortality rate is to some extent due to the fact that some of the most seriously injured are transferred to a neurosurgical hospital or are admitted directly to a neurosurgical hospital without going through the children's hospital. The great majority of head injuries are slight. The present investigation is concerned only with the seriously injured.

The material consists of 23 cases, 18 boys and five girls, during the 10-year period from 1951-1960; all survived after having been unconscious for a period of 24 hours or longer. The two most seriously injured were unconscious for 50 days. The duration of the periods of unconsciousness is shown in Table 2. The distribution by age (Table 3 ) shows a predominance of children under school age. Seventeen of the children had been injured in motor vehicle accidents, one had been thrown by a runaway horse, three had fallen out of windows and two had fallen from trees. Skull radiographs, which were taken in all cases but one, showed fracture in 12 cases, of which one was a depressed fracture, treated with elevation. There were clinical signs of fracture of the base of the skull in another three cases, but these fractures could not be verified by radiograph. Trepanning was done in five cases, but was negative in four. In one case a subdural haematoma was uncovered. The time spent in hospital varied between six days and 11 months, the average being 61 days. Fifteen of the children showed continued neurological symptoms when they were discharged from the hospital.

Nineteen of the children have had later clinical observation by us. We have also obtained information about their conditions during the observation periods through conversations with the parents. Ten of these children have, at follow-up examination, been tested with Terman-Merrill's intelligence test, and one according to the Wechsler-Bellevue scale. One child has been examined by other physicians. In two of the cases whom we have not followed up clinically, because they are living in distant parts of the country, the evaluation is based solely on conversations with relatives and teachers. No information has been received on one child. The observation period varies between six months and nine and a half years.

\section{Results}

Of those 22 cases included in the follow-up investigation (Table 4), 13 have shown remarkable neurological or psychiatric symptoms, evaluated as sequelae, while three have shown a completely normal status and six have had slight symptoms which can be attributed to causes other than head

TABLE 4

OCCURRENCE OF SYMPTOMS AT FOLLOW-UP EXAMINATION

\begin{tabular}{|c|c|c|c|c|}
\hline & \multicolumn{3}{|c|}{ Symptoms } & \multirow{2}{*}{ Total } \\
\hline & Neurological & Psychiatric & $\begin{array}{c}\text { Neurological and } \\
\text { Psychiatric }\end{array}$ & \\
\hline 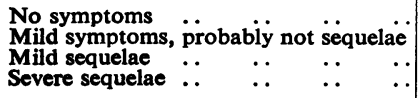 & $\frac{\overline{6}}{6}$ & $\begin{array}{l}-6 \\
1 \\
-\end{array}$ & $\overline{\bar{z}}$ & $\begin{array}{l}3 \\
6 \\
7 \\
6\end{array}$ \\
\hline
\end{tabular}


injury. Of the 13 children who have had resulting sequelae it can be shown that seven have only neurological sequelae, one only psychiatric and five have both neurological and psychiatric.

Three of the children have such serious symptoms as to cause severe invalidism. Those concerned are a boy with pronounced cerebral palsy and intellectual retardation, another boy with pronounced difficulties in school and with companions, due to personality alteration and intellectual retardation, and a girl with slight cerebral palsy and so severe a personality alteration that periodically she cannot be cared for at home.

Three of the children who have serious symptoms are not invalided. These are a girl with partially diminished hearing, psychomotor epilepsy and slight lowering of psychical level, a boy with lost sensibility in half of his face and total deafness in one ear, and a boy with facial paralysis, moderate spastic paralysis of the extremities, and slight lowering of psychical level.

Seven children have slight symptoms which are evaluated as sequelae. These include two cases with slight paralysis of extremities, three with impaired hearing, one with a very slight speech disturbance and one with slight lowering of psychical level and post-traumatic neurosis.

There is no certain correlation between the duration of unconsciousness and the degree of severity of symptoms. Four children with unconscious periods of relatively short duration have serious symptoms while one boy, after 17 days' unconsciousness, is without sequelae, and another boy, who was unconscious for 28 days, has only a very slight paralysis of his left leg.

\section{Discussion}

A number of these children had, at the time of discharge, shown serious neurological signs and symptoms which appeared to regress rapidly after physical therapy treatment, in most cases during the course of a single year. Only in one case are the remaining neurological symptoms so serious that the child has a severe motor handicap. Those others with remaining neurological symptoms at the time of follow-up examination are comparatively slightly invalided, and in some cases the observation period has been so short that there is reason to expect additional improvement.

Post-traumatic epilepsy has resulted in only one case and is moderately slight in character.

The duration of unconsciousness did not seem to have great value as a prognostic sign. Many writers (Adebahr, 1959, among others) have held that this could be the case in that unconsciousness in itself could cause damage to the central nervous system. In our material many children with longterm unconsciousness have been symptom-free.

No less than nine children have shown themselves to be intellectually retarded, and in most cases it is moderately well pronounced (equivalent to mental dullness). That the nature of these retardations had some connexion with the head injury could not, in all cases, be definitely established. In most of the cases the case history points to the probability that the retardation of intellect might be constitutional in origin, in that oligophrenia was present in either the parents or the brothers and sisters, or that the child, before the accident, had had pronounced difficulties in school, indicating a possible oligophrenia. In one case the resulting retardation parallels serious neurological symptoms, indicating widespread damage to the nervous system. Involved here is a serious retardation (comparative imbecility), and side by side with it aphasia. The case history in this instance indicated that the intellect was satisfactory before the head injury. That the number of intellectually retarded children in this investigation is high corresponds with what one would expect in children who are accident cases. This has been shown previously by, among others, Wallberg (1957) and R. Berfenstam (personal communication).

In those cases where positive psychiatric sequelae occurred, simultaneous neurological symptoms regularly appeared, indicating injury to the central nervous system. Psychiatric symptoms alone, which could be said definitely to be sequelae of the head injury, appeared only in one case. The observation period in this case was only six months and there is reason to evaluate the prognosis as very favourable.

At the time of discharge, some cases showed a series of grave psychiatric symptoms, but at the time of follow-up they were symptom free. According to information which appeared reliable, such improvements have come as much as three years after the head injury. To make a definite prognosis, therefore, it is necessary to see the patient some years after the head injury, especially where it concerns higher mental functions. Those psychiatric symptoms which have been described as coming after the discharge from the hospital, have generally not been of the type which are reported as resulting from slight head injuries. Cases of characteristic motor disturbances (Goldstein, 1942) have thus only been described in a few instances. In contrast, there appeared almost without exception a pronounced, in certain cases, almost paralysing tiredness during the first days after arriving home. In many cases the speech was slow and halting, while in all cases but 
one the ability to express themselves and to understand words was satisfactory. Changed handedness occurred in two cases.

Only in the cases where injury to the central nervous system could be verified through the neurological symptom picture could permanent mental scars be demonstrated with certainty. In the rest of the cases, even in those with long-term unconsciousness, psychiatric symptoms, some of them serious, have appeared at first, but only temporarily, or not at all. From the prognostic standpoint there is, therefore, probably cause to view with optimism those cases which at the time of discharge from the hospital had only psychiatric symptoms. Improvement has been observed in some cases which at the time of discharge had serious neurological symptoms. Therefore there is reason to evaluate long-term prognosis for children with severe head injuries as moderately good, even in cases where unconsciousness had been long-term and where serious symptoms have resulted in the acute stage.

\section{Summary}

Twenty-two children from 1 to 14 years of age treated at Kronprinsessan Lovisas Barnsjukhus in
Stockholm for severe head injuries during a 10-year period have been followed up six months to nine and a half years after the injury.

The duration of unconsciousness has varied from one to 50 days.

The follow-up examination shows nine cases to be free from neurological and psychiatric sequelae, while 13 are shown to have sequelae. Only in six of these worst cases were the sequelae severe and in three cases serious invalidism occurred.

Even cases which at the time of discharge had shown serious neurological or psychiatric symptoms were at the time of follow-up completely free from symptoms. Improvement was indicated to have come years after trauma.

No correlation was found between the duration of unconsciousness and the severity of the sequelae.

\section{REFERENCES}

Adebahr, G. (1959). Brain changes after post-traumatic uncon sciousness of one week's duration. Dtsch. Z. ges. gerichtl. Med., 49, 680 .

Åkerlund, E. (1959). The late prognosis in severe head injuries. Acta chir. scand., 117, 275.

Cedermark, J. (1942). UUber Verlauf, Symptomatologie und Prognose kraniozerebraler Verletzungen. ibid., 86, Suppl. 75.

Goldstein, K. (1942). After Effects of Brain Injuries in War. Grune and Stratton, New York.

Wallberg, K. (1957). Children in Traffic. Stockholm. 